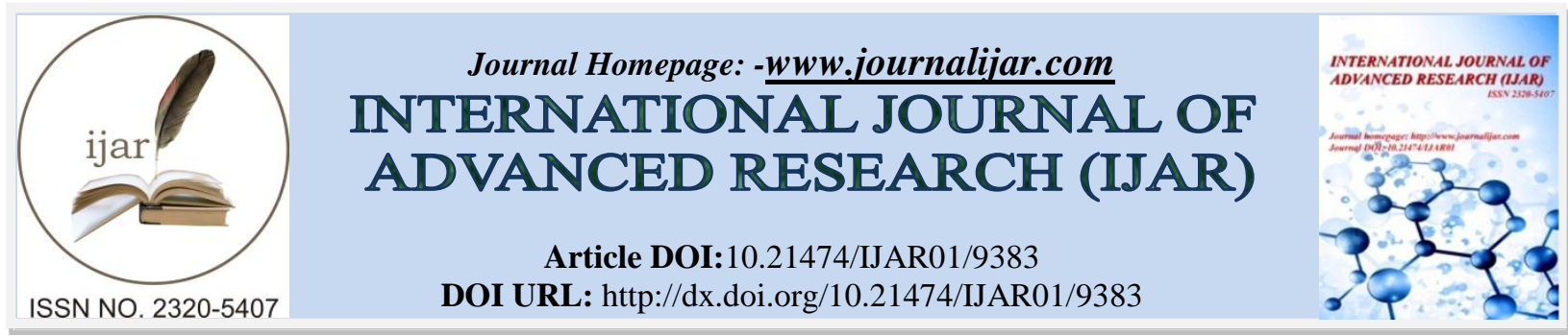

RESEARCH ARTICLE

\title{
A STUDY OF THE IMPACT OF DIETARY HABITS ON TYPE II DIABETIC RETINOPATHY CORRELATING WITH HBA1C LEVELS, AMONG PATIENTS ATTENDING A TERTIARY CARE HOSPITAL ATTACHED TO ANDHRA MEDICAL COLLEGE, VISAKHAPATNAM, ANDHRAPRADESH.
}

\section{Dr. NirmalaJyothiPamu ${ }^{1}$ and Dr.N.B.Vijaya Kumar ${ }^{2}$.}

1. Designated Associate Professor of Ophthalmology,Andhra medical college Visakhapatnam.

2. Professor of General Medicine.

\section{Manuscript Info}

..........................

Manuscript History

Received: 10 May 2019

Final Accepted: 12 June 2019

Published: July 2019

Key words:-

Broiled Food,

HbA1c,ROS,AGE,RAGE.

\section{Abstract}

Background: Type 2 diabetes, right nowaffecting almost $10 \%$ of the population, is one of the most frequently encountered metabolic disorders in India.Almost every organ in the body can be adversely affected with the onset of diabetes and its incidence is increasing day by day.Though diabetes is caused by a complex interaction of genetic and lifestyle factors.the most obvious reason for this increase especially in the number of young diabetics is their frenetic lifestyle and dietary habits.The type of food and the way it was prepared (Boiled or Broiled) that was most commonly consumed was also making a significant difference on the outcome of the diabetic complications and $\mathrm{HbAlc}$ levels there by the incidence of retinopathy. Most of the junk foods now being consumed by us come under the group of broiled food. The re-usage of the oils in the preparation of fried junk foods also makes a huge difference in making the $\mathrm{HbAlc}$ raise in the Diabetics.

Aims of the study:To review the role of food habits (boiled versus broiled food intake) in the development of Diabetic retinopathy and correlating with $\mathrm{HbA} 1 \mathrm{c}$ levels.

Methodology:50 Diabetic patients were enrolled in this study, with a slandered form of questionnaire. They were reviewed on an outpatient basis in regular intervals with their blood reports. Each patient was examined for diabetic retinopathy and noted.

Results: Our study confirms the relation between the dietary habits and the diabetic retinopathy, as there is an increasing trend in theHbAlc levels, in those who were consuming broiled food intake, like deep fried junk foods.

Conclusions: In this study it was observed that only $37 \%$ of patients who were mainly on boiled food dietary habit were having poor levels HbA1c, when compared with broiled food eaters it was 59\%. This observation correlated with the diabetic retinopathy being more in the broiled food eaters, when compared with boiled food dietary habit people. It was now very evident that avoiding the consumption of broiled food and deep fried junk food, decreases the AGE, there by decreases the diabetic vascular complications. 


\section{Introduction:-}

Type 2 diabetes, affecting almost nearing $10 \%$ of the population, is one of the most frequently encountered metabolic disorders in India. Almost every organ in the body can be adversely affected with the onset of diabetes, even in the pre diabetic state was alarming and its incidence is increasing day by day. Of course with the ignorance in our community about the possible causative factors that must be clearly delt with, in order to control its incidence and there by the rate of complications.

With timely intervention and care, this metabolic disorder can be kept under check.For this to achieve, both the patient and the health provider must be well versed with the aggravating factors and their remedies, of course it is not a simple task.

Out of 422 million Diabetics globally, India alone houses over 62 million diabetics. This is expected to rise to 552 million $(9.9 \%$ ) by $2030(1)$.Astunning forecast is that this figure is going to be 100 million diabetics in our country alone by 2030. This is an unbelievable and of course a frightening fact too, is may be due to the increased longevityand an increased obesity in India, that is a well-known and a clear-cut factthat we witness in the population in our country. It isa clear fact, that is known to all of us that more than 70 per cent of middle aged Indians, are going to suffer with type 2 diabetes during their lifetime, as we were witnessing. This is as per the results of a 10 -year analysis of data, from Southern India (1994 - 2004) that clearly revealed that there is a trend towards a rapidly increasing prevalence of diabetes in our country, in both urban and rural population, with more number of younger persons being affected, particularly women.The question is why young people are more affected by this metabolic disorder is to be thought off. Is it due to the increased longevity or it is due to the change in the dietary habits, the timing of food intake, the type of food prepared that was consumed that were leading to this metabolic disorder over a period of time must be seriously thought off.

Though diabetes is caused by a complex interaction of genetic and lifestyle factors, the most obvious reason for this increase in the number of young diabetics in India, is obviously due to the increased obesity in the young generation and their frenetic lifestyle. Now the average age of onset of diabetes is 42 years in India, which may go down further. We must reconsider the fact that the high-calorie diet along with low-activity lifestyle of Indians makes them more susceptible to this metabolic disorder. The poorly controlled DM lead to numerous complications especially involving kidney, eyes ,CVS and nerves( 2)

Awareness is important, but acceptance of the facts is even much more important,as more than one million deaths are due to diabetes alone, each year in our country.

The type of food and the way it was prepared (Boiled or Broiled) that was most commonly consumed as a habit by the person was also making a significant difference on the outcome of the diabetic complications and HbA1c levels, there by affecting the incidence of retinopathy. Most of the junk foods now being consumed by us come under the group of broiled food. The re-usage of the oils in thepreparation of fried junk foodsalso makes a huge difference, in making the HbA1c to rise in the Diabetic patients, as they contain huge amounts of AGE in them, leading to oxidative stress.

This study will certainly help in bringing the awareness of the health care people, and the patients about the importance of dietand the way it was prepared (as compared with boiled versus broiled food intake)in diabetic patients management and thereby reducing the diabetic retinopathy and the other micro and macro vascular complications that are commonly seen in the diabetic patients.

\section{Methodology:-}

An out outpatient based, observational study conducted in between December 2014 to May 2015, among Patients Attending a Tertiary Care hospital, King George Hospital, Visakhapatnam, Andhrapradesh, South India.

A total number of 50 Diabetic patients were enrolled in this study, with a standard proforma of questionnaire. An informed consent was taken from all of them and those who are willing to participate were only included in this out outpatient based observational study. 
They were reviewed in regular intervals, on an outpatient basis,along with their blood reports. Each patient was examined for diabetic retinopathy and noted the findings. A complete dietary habit history was taken, at every two to three weekly intervals, with special reference to theboiled versus broiled food intake (junk food included).

Anthropometric measurements like height weight and blood pressure were noted along with the blood glucose levels at regular intervals. An ophthalmic examination and an Hba1c level were done to all the participants at the beginning and at the end of the study, for comparison.

\section{Results:-}

A total number of 50 Diabetic patients of both sexes were enrolled in this study, from both rural and urban population. The age group of the study population ranged from $41-80$ years. In this study it was observed that $83 \%$ of patients who were mainly on broiled food and junk food dietary habits were having a high BMI, when compared with boiled food eaters it was only $78 \%$.

In this study it was also observed that $59 \%$ of patients who were mainly on broiled food eaters (includes the deep fried junk food) were having poor levels HbA1c, where as when compared with boiled food eaters it was only 37 $\%$.An obvious difference was noted in this present study and this observation correlated with the diabetic retinopathy, being more in the broiled food eaters, when compared with the people who are having a boiled food dietary habit.

Boiled and Broiled food consuming habits Vs HbA1c.

\begin{tabular}{|ll|l|l|l|l|l|l|l|}
\hline & $\begin{array}{l}\text { Total } \\
\text { participants }\end{array}$ & $\begin{array}{l}\text { Normal } \\
\text { HbA1c }\end{array}$ & $\%$ & $\begin{array}{l}\text { Fair } \\
\text { HbA1c }\end{array}$ & \% & $\begin{array}{l}\text { Poor } \\
\text { HbA1c }\end{array}$ & $\%$ \\
\hline $\begin{array}{l}\text { Boiled food } \\
\text { Eaters }\end{array}$ & $\mathbf{3 8}$ & 4 & 10 & 20 & 53 & 14 & 37 \\
\hline $\begin{array}{l}\text { Broiled food } \\
\text { Eaters }\end{array}$ & 12 & 1 & 8 & 4 & 33 & 7 & 7 \\
\hline
\end{tabular}

Fig 1:-Patients with Boiled food consuming habits Vs HbA1c levels.

\section{Sales}

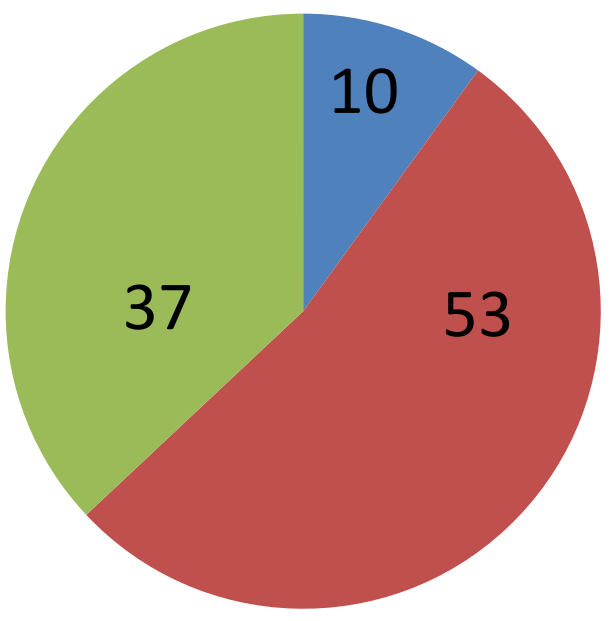

Normal HbAic

- Fair HbAic

Poor HbAic 
Fig 2:-Patients with Broiled food consuming habits Vs HbA1c levels.

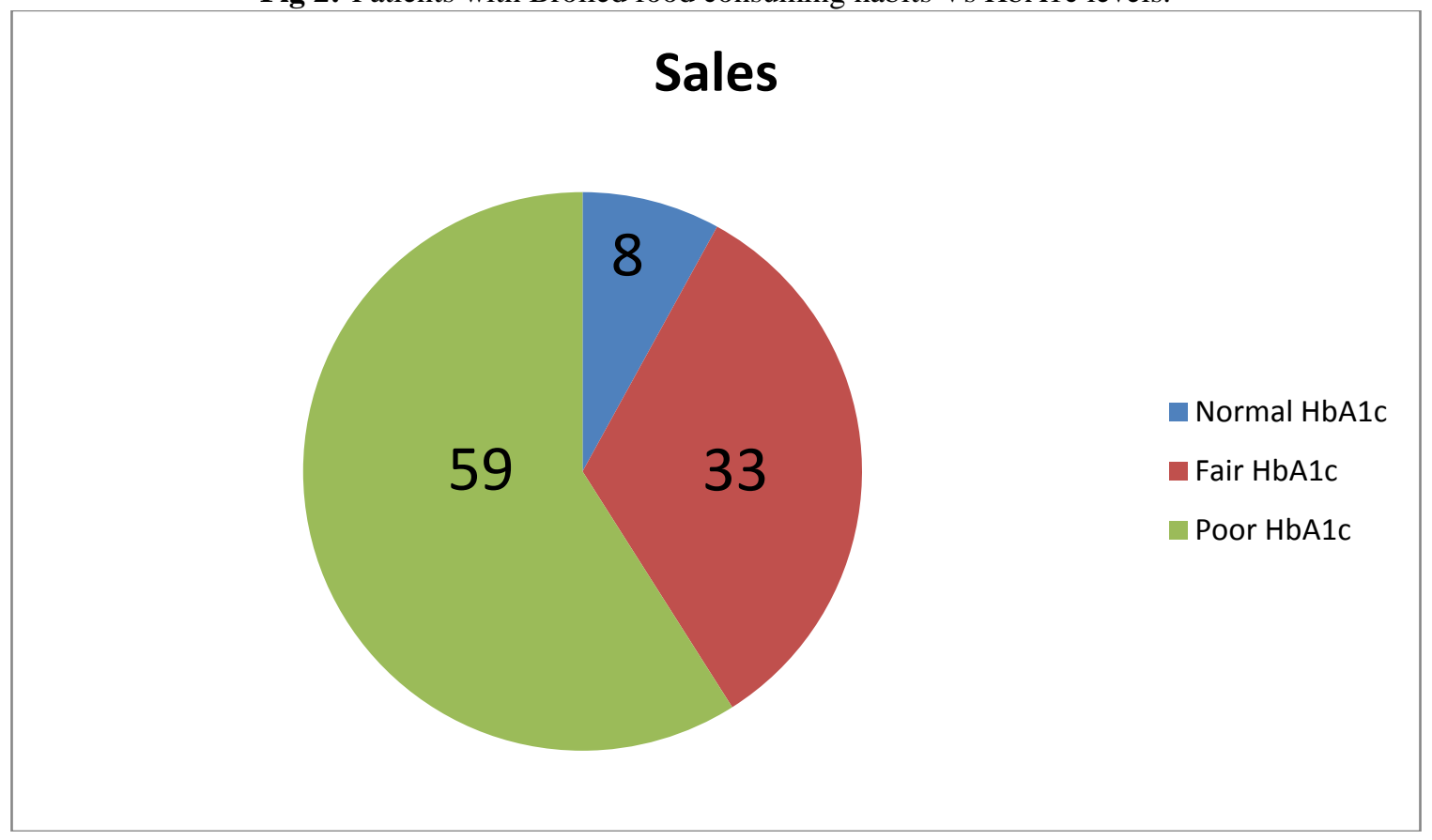

\section{Discussion:-}

The scope of this study involves analysing the life styles of patients and their dietary habits and its relation in the development of diabetic complications like retinopathy, to help the health care personnel in preventing and controlling the diabetes.

Diabetes is rapidly reaching a state of a potential epidemic in India, with more than 62 million diabetic patients diagnosed with this metabolic disorder, which is more than $7 \%$ of the adult population in 2000, (31.7 million).Right now India topped the world with the highest number of diabetes mellitus patients. China (20.8 million) and the United States (17.7 million) occupying the second and third places respectively. With further rapid increasing figures of freshly diagnosed patients, especially in younger populations, India right now facing an uncertain future, in relation to the possible burden that this metabolic disorder may impose upon the country economy.

As a means of identifying current practices that are involved in the development of diabetes and understanding the role of life style modification and dietary habits in preventing and controlling the diabetes and its complications, the present study focused mainly on the consumption of boiled or broiled food preparations and their effect on HbA1c levels.

Many factors may affect the prevalence of diabetes in our country, and proper identification of those factors is very much important and necessary to facilitate for a reduction of its prevalence and control. This study mainly focuses on one of the possible factors currently affecting diabetes in India. Is it a bad life style and or combined with bad food habits.Many influences affect the prevalence of disease throughout a country, and identification of those factors is necessary to facilitate change when the patients are facing health challenges. So what are those factors currently affecting diabetes in India thatis making this problem so extreme? Is it bad life style and bad food habits?

It is a well-known fact that most of the Indians consume a very high calorie diet, leading to hyper glycaemia. The both intermittent and stable hyper glycaemia were harmful for our body.Intermittent high glucose versus exposure to stable high glucose environment revealed that there was an increased apoptosis of endothelial cells that were exposed to intermittent high glucose. This may be related to ROS overproduction.In euglycemia themitochondria produce ATP, where as in Hyperglycemia Mitochondria produce Reactive oxygen species (ROS) that can damage the cell. The extracellular oxidative stress increases globally in both type 1 diabetes and type 2 diabetes $(3,4)$ These Reactive oxygen species (ROS) are the main culprit and cause in the development of diabetes complications and pathogenesis. 
These free radicals are formed through non-enzymatic glycation reactions, through mitochondrial electron transport chain dysfunctions, in the presence of hyperglycaemia, especially in an environment intermittent hyper glycaemia.

ROS disrupt the transmission pathways between the insulin receptor and glucose transport system, leads to insulin resistance. ROS also inactivate the two critical anti-atherosclerotic enzymes: Endothelial Nitric Oxide, Prostacyclin Synthase. That damages the vascular endothelium. Since ROS can induce DNA damage and both are increased in diabetes $(5,6)$

ROS also participate in the formation of Advanced Glycated End products (AGE).These AGE induce cross linkation processes in the structure of proteins (collagen), modifying blood vessel structure. AGEs often accumulate intracellularly (7) . AGE by binding to their specific receptors (RAGE), they activate Intracellular signalling pathways leading to cytokine production, that is again responsible for the pro-inflammatory and pro-sclerotic effects.Hyperglycemia in addition to elevated Free Fatty Acids and Insulin resistance leads to Oxidative Stress leading to Vasoconstriction, Inflammation and a state of Hyper coagulation, all of them can finally leading to vascular damage. (8)

Decreasing GV obviously decreases the AGE.AGE is formed in our body in two ways, one is endogenously, and the second source is from exogenous sources that are from the dietary source. AGE that was consumed from the food that we regularly take makes a lot of difference in the development of diabetic complications. If you compare boiled chicken and broiledchicken( junk food preparations) for instance, the units of AGE per gram of food in boiled chicken is 9700 , and when compared with that inbroiled chicken(like that in the deep fried junk food) it is 78880 AGE units/ gram of food. A huge difference was noted in the above example. Similarly in boiled fish the AGE was 9900 AGE units/ gram of food, in broiled junk food fish fry it is 74000AGE units/ gram of food. Similarly if you take boiled potato and the French fries (the broiled food) the AGE units/ gram of food is 174 units/ gram of food and 5600 units/ gram of food respectively. It is now clear that consumption of less AGE containing diet is recommended to reduce and prevent the micro and macro vascular complications of diabetes

So what are the goals we must reach in order to decrease the diabetic complications? They are $<7.0$, FPG $70-130$ $\mathrm{mg} / \mathrm{dl}, 2$ hr PPG <180 mg/dl, GV<40 mg/dl.

It was now very evident that avoiding the consumption of broiled food and deep fried junk food, decreases the AGE remarkably through the dietary sources, there by decreases the diabetic vascular complications. It was clearly evident in the present observational study that there is an increase in $\mathrm{HbA} 1 \mathrm{c}$ in broiled food eaters.

\section{Conclusions:-}

Even though the number of patients included in this observational study was less (50 patients), it was clearly observed that there was a significant relation between the HbA1c levels and the dietary habits (boiled versus broiled food intake) making a huge difference in causing diabetic micro and macro vascular complications like retinopathy. These observations were may be related to the high levels of AGE (Advanced Glycation End Products) present in the broiled foods, especially broiled junk foods, as they were available in every street corner or in the restaurants of most of the cities in India, at any time, you can say twenty four hours a day. One more factor was the timing of food intake of our people in our country.May be we are the late eaters of high caloric dinner (in 24 hours when compared with the breakfast and lunch). May be our eating habits of the highest caloric late diner, when compared with the other countries in this word, must be another reason. It is the correct time that we must seriously think off a life style modification of ours (as we were deviated drastically in our life style from our older generations, as they were used to be in the pre TV era)may be that was the main cause of this increasing trend of Diabetes in India.

\section{Bibliography:-}

1. Wild S, Roglic G, Green A, Sicree R, King H. Global prevalence of diabetes: Estimates for the year 2000 and projections for 2030. Diabetes Care. 2004;27:1047-53.

2. Alberti K, Davidson MB, DeFronzo RA, Drash A, Genuth S, Harris MI, et al. Report of the expert committee on the diagnosis and classification of diabetes mellitus. Diabetes Care. 1998;21:S5.

3. VanderJagt DJ, Harrison JM, Ratliff DM, Hunsaker LA, Vander Jagt DL. Oxidative stress indices in IDDM subjects with and without long-term diabetic complications. Clin Biochem. 2001;34(4):265-270. 
4. Keaney JF, et al. Obesity and systemic oxidative stress: clinical correlates of oxidative stress in the Framingham Study. Arterioscler Thromb Vasc Biol.2003;23(3):434-439.

5. Wu LL, Chiou CC, Chang PY, Wu JT. Urinary 8-OHdG: a marker of oxidative stress to DNA and a risk factor for cancer, atherosclerosis and diabetics. Clin Chim Acta. 2004;339(1-2):1-9.

6. Kang D, Hamasaki N. Mitochondrial oxidative stress and mitochondrial DNA. Clin Chem Lab Med. 2003;41(10):1281-1288.

7. Giardino I, Edelstein D, Brownlee M. Nonenzymatic glycosylation in vitro and in bovine endothelial cells alters basic fibroblast growth factor activity. A model for intracellular glycosylation in diabetes. J Clin Invest. 1994;94:110-117

8. Zheng F, He C, Cai W, Hattori M, Steffes M, Vlassara H. Prevention of diabetic nephropathy in mice by a diet low in glycoxidation products. Diabetes Metab Res Rev. 2002;18:224-237. 